JiSEA
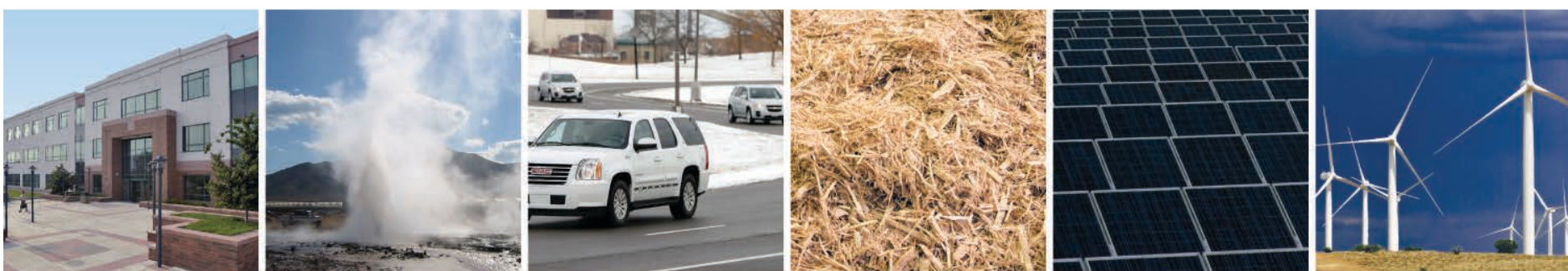

\title{
Natural Gas and the
}

Transformation of the U.S.

Energy Sector:

A Program Studying Multi-sector Opportunities and Impacts

\author{
Scott Gossett \\ National Renewable Energy Laboratory
}

The Joint Institute for Strategic Energy Analysis is operated by the Alliance for Sustainable Energy, LLC, on behalf of the U.S. Department of Energy's National Renewable Energy Laboratory, the University of Colorado-Boulder, the Colorado School of Mines, the Colorado State University, the Massachusetts Institute of Technology, and Stanford University.

Workshop Summary

NREL/TP-6A50-57726

January 2013

Contract No. DE-AC36-08GO28308 


\title{
Natural Gas and the
}

Transformation of the U.S.

Energy Sector:

\section{A Program Studying Multi-sector Opportunities and Impacts}

\author{
Scott Gossett
}

National Renewable Energy Laboratory

Prepared under Task No. 6A50.1025

The Joint Institute for Strategic Energy Analysis 15013 Denver West Parkway Golden, CO 80401 303-275-3000 • www.jisea.org
The Joint Institute for Strategic Energy Analysis is operated by the Alliance for Sustainable Energy, LLC, on behalf of the U.S. Department of Energy's National Renewable Energy Laboratory, the University of Colorado-Boulder, the Colorado School of Mines, the Colorado State University, the Massachusetts Institute of Technology, and Stanford University.

JISEA $^{\circledR}$ and all JISEA-based marks are trademarks or registered trademarks of the Alliance for Sustainable Energy, LLC.

\section{Workshop Summary}

NREL/TP-6A50-57726

January 2013

Contract No. DE-AC36-08G028308 


\section{NOTICE}

This report was prepared as an account of work sponsored by an agency of the United States government. Neither the United States government nor any agency thereof, nor any of their employees, makes any warranty, express or implied, or assumes any legal liability or responsibility for the accuracy, completeness, or usefulness of any information, apparatus, product, or process disclosed, or represents that its use would not infringe privately owned rights. Reference herein to any specific commercial product, process, or service by trade name, trademark, manufacturer, or otherwise does not necessarily constitute or imply its endorsement, recommendation, or favoring by the United States government or any agency thereof. The views and opinions of authors expressed herein do not necessarily state or reflect those of the United States government or any agency thereof.

Available electronically at http://www.osti.gov/bridge

Available for a processing fee to U.S. Department of Energy and its contractors, in paper, from:

U.S. Department of Energy

Office of Scientific and Technical Information

P.O. Box 62

Oak Ridge, TN 37831-0062

phone: 865.576 .8401

fax: 865.576 .5728

email: mailto:reports@adonis.osti.gov

Available for sale to the public, in paper, from:

U.S. Department of Commerce National Technical Information Service 5285 Port Royal Road Springfield, VA 22161 phone: 800.553 .6847 fax: 703.605.6900

email: orders@ntis.fedworld.gov

online ordering: http://www.ntis.gov/help/ordermethods.aspx

Cover Photos: (left to right) PIX 12721, PIX 13995, @ GM Corp., PIX 16161, PIX 15539, PIX 16701

Printed on paper containing at least $50 \%$ wastepaper, including $10 \%$ post consumer waste. 


\section{Executive Summary}

In recognition of the major transitions occurring within the U.S. energy economy, the Joint Institute for Strategic Energy Analysis (JISEA) and Stanford University's Precourt Institute for Energy (PIE) engaged diverse energy system stakeholders in a discussion about robust, objective, and timely research priorities relating to natural gas. Held December 10-11, 2012 on the Golden, Colorado campus of the National Renewable Energy Laboratory (NREL), the workshop provided invited experts from government, industry, academia, and the environmental community an opportunity to describe the state of current knowledge in defined topic areas, and to suggest analytic priorities for ongoing research. Following discussion, stakeholders prioritized research questions through an interactive voting process.

This record of proceedings is not a comprehensive recording of the event; rather, it focuses on key issues raised. To encourage honest and open discussion, session notes were recorded without attribution. Where appropriate, the report summarizes the key matters of discussion, and attempts to provide a sense of areas of consensus and divergence among the workshop participants.

\section{About JISEA}

The Joint Institute for Strategic Energy Analysis (JISEA) conducts interdisciplinary researchrealized through teams drawn from the founding partners and a network of national and global affiliates - and provides objective and credible data, tools, and analysis to guide global energy investment and policy decisions. JISEA is focused on providing leading analysis; guiding decisions on energy, investment, and policy; and answering questions that enable a cost-effective transition to sustainable energy at significant speed and scale, while minimizing unintended impacts.

JISEA is operated by the Alliance for Sustainable Energy, LLC, on behalf of the U.S. Department of Energy's National Renewable Energy Laboratory (NREL), the University of Colorado-Boulder, the Colorado School of Mines, the Colorado State University, the Massachusetts Institute of Technology, and Stanford University. Each institution brings a unique set of capabilities to the partnership.

Learn more at JISEA.org.

\section{About PIE}

The Precourt Institute for Energy serves as the hub of energy research and education at Stanford University. Established in 2009, the Precourt Institute seeks to transform energy by supporting cutting-edge research and facilitating collaboration. We also help develop energy-literate leaders and communities through educational programs and the dissemination of research results.

Stanford's broad network of world-class researchers working on energy-related problems spans more than 200 faculty members working in 22 academic departments and more than two dozen independent labs and programs. By creating formal and informal links, the Precourt Institute fosters opportunities for scientists, engineers, social scientists, and legal and business scholars to solve the world's energy problems.

Learn more at Energy.Stanford.edu. 


\section{Table of Contents}

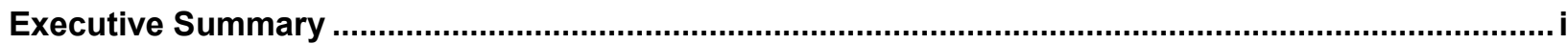

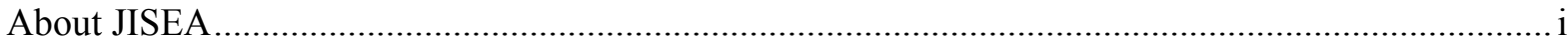

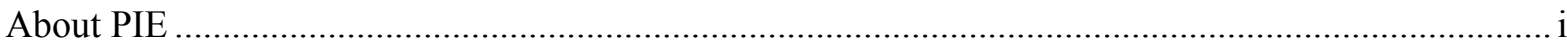

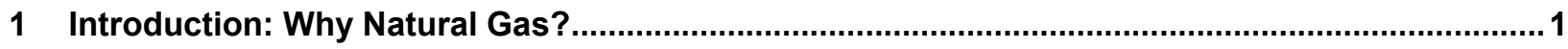

2 Informing a Research Agenda

2.1 Dynamics of Natural Gas in the United States and Globally .....................................................

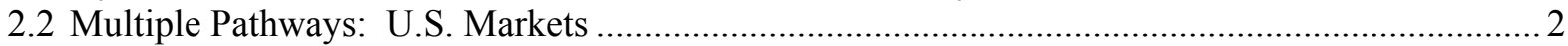

2.3 Production and Distribution Issues: Environment and Infrastructure ......................................... 3

2.4 JISEA Natural Gas Power Sector Study and Insights from the Field ....................................... 3

2.5 Metrics: A Broad Look Across Impacts...................................................................................

2.6 Opportunities and Challenges in the Transportation Sector....................................................... 5

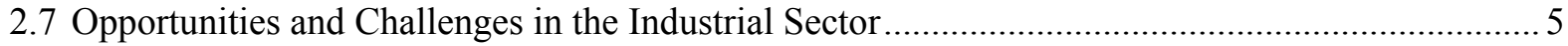

2.8 Opportunities and Challenges in the Buildings Sector............................................................. 5

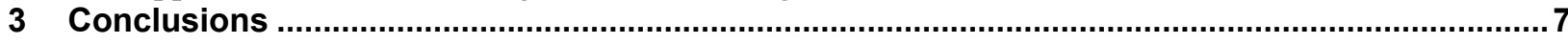

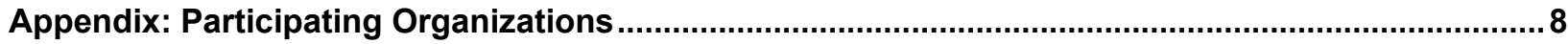

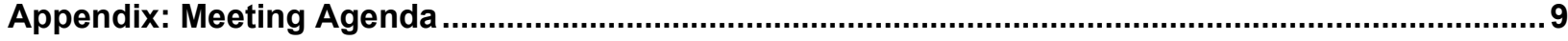




\section{Introduction: Why Natural Gas?}

The United States is experiencing a shale gas revolution. Advances in drilling and recovery methods allow access to reserves and resources inaccessible just a few years ago. As recently as 2007, the U.S. Department of Energy was studying how to meet demand for natural gas imports. Today, U.S. energy policy makers find themselves trying to understand the domestic and global implications of a booming U.S. natural gas market, including the potential for U.S. exports.

Figure 1 depicts the very rapid rise in U.S. shale gas production beginning in around 2007. In an early release of its 2013 Annual Energy Outlook (AEO), the U.S. Energy Information Administration (EIA) projects that shale gas production will continue to grow, and comprise more than $40 \%$ of overall U.S. gas production by 2040 . This change of events could lead to cheaper fuels, greater energy security, and lower greenhouse gas (GHG) emissions. However, near-term choices about how to use this new resource could result in more long-term harm than good.

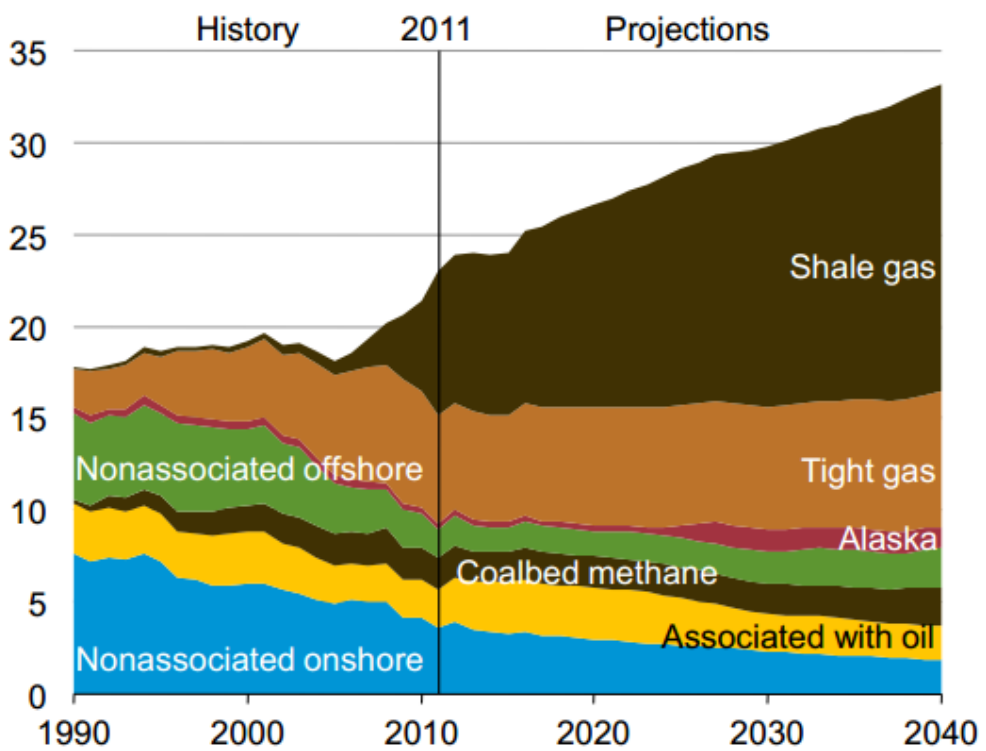

Figure 1: U.S. dry natural gas production by source 1990-2040 (TCF) (AEO 2013)

In recognition of the importance of the shale gas revolution on the U.S. energy economy, the sponsors engaged energy system stakeholders from government, industry, academia, and the environmental community on natural gas research priorities. The natural gas revolution has opened up new questions for both public and private sector stakeholders.

Some of these questions center on the extent to which the circumstances driving the shale gas revolution are perhaps uniquely American. Private ownership of mineral rights is almost unique to the United States, as is development on private lands. These circumstances may confine the boom in shale gas production largely to the United States, but the effects of that boom will be felt globally. Gas that had been slated for use in the United States could find a use elsewhere. Already, this is leading to gas-on-gas competition in Western Europe, and spurring more trading on spot markets rather than long term (25 year) contracts. Production companies are forced to meet the market, and that trend (based on oil market experience) may be difficult to reverse. 


\section{Informing a Research Agenda}

At the workshop, invited experts described the current state of knowledge in eight defined topic areas, and suggested analytic research priorities for each. During presentation of each topic area, an assigned commentator summarized key themes and posed probing questions to spur discussion.

All stakeholders contributed potential research questions for each topic during two broad discussion sessions. Stakeholders then discussed prioritization of the topics, geared toward formulating a research agenda that will allow resilient decisions in the face of market and policy uncertainty.

The exact prioritized research agenda identified by stakeholders is not presented in detail here, although may be requested by interested parties by contacting JISEA.

\subsection{Dynamics of Natural Gas in the United States and Globally}

This session described the hot topics, issues, and projections for global natural gas, with particular focus on the North American market.

The shale gas revolution affects four major economic sectors - industrial, transportation, residential/commercial, and power generation - with the greatest potential impacts, as currently understood, in the last. In Organization for Economic Cooperation and Development (OECD) countries, demand for gas is forecast to grow to 200 billion cubic feet per day (bcf/d) by 2040, about one third higher than today's demand. This could result in lower costs for electricity and increased environmental benefits, such as lower emissions of SOx, NOx, and greenhouse gasses compared to coal, provided methane emissions are controlled.

To meet projected production of natural gas, the United States could see 100,000 new wells and 1 million fractures in the next 10 years. Despite potential GHG emissions benefits of natural gas, shale gas production is not without environmental concerns, including safety of the drilling process; water use required for hydraulic fracturing process; potential for contamination of ground and surface waters; and possible fugitive methane emissions.

Selected illustrative research questions identified by stakeholders in this session included:

- Will the shale gas production boom go global? When? Where? Impacts?

- What are the economic impacts of using natural gas across multiple sectors-power generation, export, industrial, and transportation?

- What are economic and climate impacts of using domestic natural gas in the industrial sector compared to exporting liquefied natural gas?

\subsection{Multiple Pathways: U.S. Markets}

This session provided an overview of natural gas uses in different U.S. market sectors, and participants examined various modeling activities and techniques.

EIA's Annual Energy Outlook (AEO) models projections based on current law and policy. Thus, it does not predict potential or hypothetical developments, such as implementation of a carbon tax. According to AEO2012, U.S. natural gas production grows robustly, driven by the advent of shale gas. AEO2012 projects that the United States will become a net exporter of natural gas by 2020, 
two years earlier than the prior report. Many of these exports will be to Canada and Mexico, and will displace some coal production and consumption.

EIA also foresees increased use of natural gas in the manufacturing sector, and discussion addressed the need to understand if the overall economic impact of natural gas-fueled manufacturing outweighs that of natural gas exports.

Discussion suggested looking more closely at modeling inputs, such as pricing and supply curves, and addressed several topics regarding current models, such as factors in models that make it more advantageous to export natural gas rather than use it to offset domestic coal use, and whether models accurately forecast natural gas penetration in the transportation sector.

Selected illustrative research questions identified by stakeholders in this session included:

- Is it more beneficial to use natural gas directly to support renewable energy or indirectly as energy storage?

- How might "black swans," tipping points, disruptive innovation and other unknowns impact the role of natural gas?

- What is the long term outlook for natural gas production and penetration based on resource cost curves?

\subsection{Production and Distribution Issues: Environment and Infrastructure}

This session addressed important production and distribution issues, including concerns about water use and fugitive emissions. In public perception, hydraulic fracturing (or fracking) has become an all-encompassing term that incorporates all environmental concerns related to shale gas production. In reality, fracking is one small part of the production process, and perhaps not the most important part from an environmental perspective. Well construction and well integrity are considered more important to preventing environmental damage during shale gas production.

Panelists suggested that better framing and defining the early debate around fracking and shale gas production could have led to important and different outcomes regarding actual risk versus perceived risk. It was suggested that, due to current public perceptions, enforcement of existing regulations may not be sufficient to ensure a "social license" to operate, and more effort at outreach and engagement with local communities may be necessary.

Selected research questions identified by stakeholders in this session included:

- How do GHG emissions vary by well-specific gas composition, equipment, production and estimated ultimate recovery?

- What are the sources of fugitive methane emissions and methane leaks during the different stages of production, transmission, and distribution, and options to reduce them?

\subsection{JISEA Natural Gas Power Sector Study and Insights from the Field}

In this session, participants explored key findings from JISEA's November 2012 study, Natural Gas and the Transformation of the U.S. Energy Sector: Electricity. The study provides a new approach to and evaluation of shale gas lifecycle GHG for power; an analysis of legal and regulatory frameworks associated with shale gas; and an evaluation of scenarios for power sector evolution. 
The complete study is available at JISEA.org/natural_gas.cfm. Using actual 2009 emissions data from the Barnett Shale Play in Texas, JISEA analysts found that life cycle GHG emissions from shale gas production were equivalent to unconventional and conventional natural gas production elsewhere. Follow up research could focus on expanding the study to see if findings are the same in other areas where data are available.

In discussion, participants cautioned that the United States cannot continue to see expanding natural gas use and reach the $80 \%$ reduction in emissions believed necessary to prevent the most damaging aspects of climate change unless CCS is available. Discussion also focused on how China's actions play into the global emissions picture, with a range of opinion on whether China will expand or reduce its use of coal going forward.

Some discussion focused on the need to make economic models more robust, so that they capture noneconomic factors that play into fuel choices. For example, Europe has an abundance of cheap coal and two sources of relatively expensive natural gas. But carbon mandates are driving use of more gas, which may be considered an un-economic outcome.

Selected research questions identified by stakeholders in this session included:

- What are the best market structures to encourage use of natural gas for balancing intermittent renewable energy generation?

- How do we best combine natural gas, renewables, energy efficiency, and demand response to provide low- or zero-carbon energy services to customers?

\subsection{Metrics: A Broad Look Across Impacts}

This session discussed ideas for the best quantitative metrics (including externalities) that can be used to evaluate production, transport, storage, and usage of natural gas, and the environmental and economic options available in various markets. The discussion included the relevancy of different metrics to different stakeholders, and the status and issues related to collecting, analyzing, and publishing the metrics and underlying data.

In discussion, participants voiced belief that the importance of choice of metrics is matched by the importance of clearly communicating results and meaning of analysis. Ideal metrics must be relevant to multiple stakeholders, cover a systems and local level, be quantifiable, and link to impacts. Understanding how to put indicators or importance into action is also essential. Monetizing metrics is one way of doing this. For example, can $\mathrm{CO}_{2}$ and non- $\mathrm{CO}_{2}$ emissions of natural gas be incorporated into a carbon tax or cap and trade scenario?

Discussion also recommended moving away from a "predict then act" method of modeling, and instead looking for ways to construct and choose near-term actions that shape the desired future. For example, is it possible to incentivize combinations of natural gas and renewable energy rather than scenarios where natural gas displaces renewables?

Selected research questions identified by stakeholders in this session included:

- What are the best metrics to measure societal benefits?

- How can we collect and share data to support engineering, economic, and policy analysis? 


\subsection{Opportunities and Challenges in the Transportation Sector}

This session addressed current and projected demand for natural gas in the transportation sector. Related issues included competition between compressed natural gas (CNG) and other nonpetroleum fuels, such as electricity, and considerations like fuel distribution and infrastructure.

In the case of the U.S. shale gas production boom, market forces (shale gas revolution) and policy goals (reducing petroleum dependence) seem to align. Across the country, CNG is cheaper than conventional gasoline on a gallon of gas equivalent basis wherever both are offered at the pump. Despite this, the United States deploys only $1 \%$ of the global fleet of natural gas vehicles (NGVs), and the U.S. NGVs are primarily medium- and heavy-duty vehicles rather than passenger vehicles. New corporate average fuel efficiency (CAFE) standards might encourage adoption of NGVs, as new rules give them the same incentive multiplier as plug-in hybrids. At the same time, increasing fuel efficiency may offset any increased use of natural gas as a vehicle fuel, muting the effect of any increase in NGV use on the overall market for natural gas. Methane emissions were mentioned as an issue for natural gas in transportation, because the distributed support infrastructure also distributes leakage opportunities.

In discussion, participants questioned whether the cost and difficulty of infrastructure installation might make a multi-fuel transportation sector more conceptually appealing than pragmatic.

Selected research questions identified by stakeholders in this session included:

- How do we compare transport/mobility options using multi-metric indicators?

- What drives decision-making among vehicle purchasers?

\subsection{Opportunities and Challenges in the Industrial Sector}

This session examined the current and projected demand and uses of natural gas in the industrial sector (e.g., heating fuel vs. chemical feedstock), competition with other energy sources in that sector, and important issues in that sector. Discussion centered on a potential once-in-a-lifetime competitive advantage that low-cost natural gas has given U.S. manufacturing. Because manufacturing tends to have a high multiplier effect, such that every $\$ 1$ investment in manufacturing may create $\$ 5-\$ 20$ of impact in the economy, some made the case that using natural gas for manufacturing might benefit the U.S. economy more than natural gas exports or use for transportation or elsewhere.

Selected research questions identified by stakeholders in this session included:

- How can we better attract investments to commercialize recovery of low-cost natural gas associated with shale oil production in North Dakota and elsewhere, in order to reduce flaring?

- What are the market impacts of international LNG trade in regional markets?

\subsection{Opportunities and Challenges in the Buildings Sector}

This session addressed the current and projected demand for natural gas in the buildings sector as well as competition with other energy sources in that sector. Compared to discussion projections of natural gas use in other sectors, the forecast for natural gas in the buildings sector seemed restrained. In the residential/commercial sector, natural gas use has remained flat for 40 years due to 
steady improvements in building and appliance efficiency. Some forecasts show a decline of natural gas use in residential/commercial sector due to continuing efficiency improvements.

Selected research questions identified by stakeholders in this session included:

- How do we most efficiently integrate electricity and natural gas systems to maximize delivery of low-carbon energy to end-users?

- What are the best options for advancing combined cooling heat and power (CCHP) or heatdriven cooling (desiccants, absorption, and other cycles) to leverage CCHP? 


\section{Conclusions}

The U.S. shale gas revolution has sparked new, cross-cutting discussion and raised important questions regarding impacts on economies and energy markets across the globe, both short and long term. Dialogue among a diverse stakeholder audience identified many of the emerging and interconnected questions raised by the dynamics of natural gas within the U.S. and global energy economy, spanning production and infrastructure, uses across all sectors and the environment. A robust research agenda emerged to help answer questions that business, civil society, investors and policymakers are asking. 


\section{Appendix: Participating Organizations}

American Gas Association

Carbon Management Center (CMC) at the University of Colorado

Center for Climate and Energy Solutions (C2ES)

Center for Strategic and International Studies

Center for the New Energy Economy

Chrysler Group LLC

Colorado Collaboratory

Colorado Energy Office

Colorado Oil \& Gas Association

Colorado School of Mines

Colorado State University

The Dow Chemical Company

Drive Natural Gas Initiative/AGA

Electric Power Research Institute (EPRI)

Enbridge Inc.

Encana Natural Gas

Environmental Defense Fund

Exxon Mobil Corporation

Gas Technology Institute (GTI)

GE Power \& Water

General Electric Global Research Center

IBM

IHS CERA

Joint Institute for Strategic Energy Analysis (JISEA)

Keystone Center

National Renewable Energy Laboratory (NREL)

Pacific Gas and Electric Company

Renewable and Sustainable Energy Institute (RASEI) at the University of Colorado

Sempra Energy

Southwestern Energy Company

Stanford University

Stanford University Precourt Institute for Energy (PIE)

Stanford University, Energy Modeling Forum

U.S. DOE, Office of Fossil Energy

U.S. DOE, Office of Energy Efficiency and Renewable Energy

U.S. Energy Information Administration (EIA), U.S. DOE

University of Colorado-Boulder

Westport Innovations

Xcel Energy 


\title{
Appendix: Meeting Agenda
}

JISEA

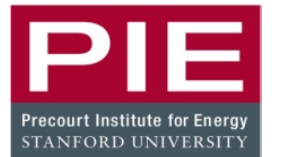

Stanford Precourt Institute for Energy

\section{NATURAL GAS AND THE TRANSFORMATION OF THE U.S. ENERGY SECTOR: A PROGRAM STUDYING MULTI-SECTOR OPPORTUNITIES AND IMPACTS}

\author{
SCOPING WORKSHOP \\ December 10-11, 2012 \\ National Renewable Energy Laboratory: Golden, Colorado
}

Monday, December 10, 2012

8:30 AM Welcome - Bobi Garrett, Deputy Laboratory Director, Strategic Programs \& Partnerships, NREL Overview - Doug Arent, Executive Director, JISEA; and Sally Benson, Director, Global Climate \& Energy Project, and Acting Director, PIE

U.S. Perspectives - Christopher Smith, Deputy Assistant Secretary for Oil \& Natural Gas in the Office of Fossil Energy, U.S. Department of Energy

9:00 AM Session 1 Setting the Scene: Dynamics of Natural Gas

Robert E. Gardner III, Manager, Corporate Strategic Planning, Energy and Economics, ExxonMobil Corporation

Lynn Orr, Director, PIE

Commentator: Morgan Bazilian, Deputy Director, JISEA

10:45 AM

12:15 PM

1:45 PM

3:30 PM

4:30 PM

Session 2 Multiple Pathways: U.S. Markets

Hill Huntington, Executive Director, Stanford University's Energy Modeling Forum John Conti, Assistant Administrator for Energy Analysis, U.S. Energy Information Administration, U.S. Department of Energy

Commentator: Joel Swisher, Associate Professor, Stanford University

Luncheon Keynote Speaker - Edward Chow, Senior Fellow in the Energy and National Security Program, Center for Strategic and International Studies (CSIS)

Session 3 Production and Distribution Issues: Environment and Infrastructure Mark Boling, President of V+ Development Solutions, Southwestern Energy Company Mark Brownstein, Deputy Director, Environmental Defense Fund, Energy Program Commentator: Elizabeth Paranhos, J.D., Senior Research Fellow, University of Colorado Law School

Session 4 Summary of the JISEA Natural Gas Power Sector Study and Insights from the Field Jeff Logan, Senior Energy Analyst, NREL Bryan Hannegan, VP Environment and Renewables, EPRI Commentator: Janet Peace, VP Markets and Business Strategy, Center for Climate and Energy Solutions (C2ES)

Session 5 Metrics: A Broad Look Across Impacts

Margaret Mann, Group Manager, Technology Sustainability and Systems Analysis, NREL 
Adam Brandt, Assistant Professor in the Department of Energy Resources Engineering at Stanford University

Commentator: Sally Benson, Acting Director, PIE; Professor of Energy Resources Engineering, Stanford University; and Director of Global Climate Energy Project (GCEP)

6:00 PM Reception

6:30 PM Reception Speaker - The Honorable Bill Ritter, Jr., former Governor of Colorado, Director of the Center for the New Energy Economy

8:00 PM Adjourn

Tuesday, December 11, 2012

8:30 AM Session 6 Discussion of Prioritization of First Day's Key Research Questions

9:15 AM Session 7 Opportunities and Challenges in the Transportation Sector

Kathryn Clay, Executive Director, Drive Natural Gas Initiative

Commentator: Margo Melendez, Technology Deployment Manager, NREL

10:15 AM Session 8 Opportunities and Challenges in the Industrial Sector

George Biltz, Vice President, Energy and Climate Change, The Dow Chemical Company

Commentator: Dag Nummedal, Director, Colorado Energy Research Institute, Colorado School of Mines

11:00 AM Session 9 Opportunities and Challenges in the Buildings Sector

Steve Malnight, Vice President, Customer Energy Solutions, Pacific Gas \& Electric Jack Lewnard, Vice President and Chief Technology Officer, Gas Technology Institute Commentator: Paula Gant, Senior Vice President, Policy and Planning, American Gas Association

12:00 PM Session 10 Key Scenarios and Next Steps (Working Lunch)

1:45 PM Optional tour of NREL Research Support Facility (RSF) 